\title{
Incidental Vocabulary Acquisition as Student Performance Determinant in Undergraduate Research Modules
}

\author{
Joyce West \\ Correspondence: Joyce West, Department of Education, Aros, RSA. \\ Received: August 13, 2017 \\ doi:10.11114/jets.v5i10.2588 \\ Online Published: September 18, 2017 \\ Accepted: September 12, 2017 \\ jets.v5i10.2588
}

\begin{abstract}
Vocabulary knowledge plays an important role in determining a person's language proficiency level. This study investigates the role vocabulary plays in determining students' performance within research modules at private higher education institutions (HEIs). The discipline-specific vocabulary in this study includes target words, sampled from an undergraduate research module's prescribed textbook. A mixed-method design is used to explain students' challenges and concerns with regard to research modules. An investigation is launched into students' research vocabulary acquisition by administering pre- and post-testing with regular reliability. By measuring the students' research vocabulary acquisition, the effectiveness of the research module's (mostly incidental) learning process is determined. The relationship between the students' research vocabulary acquisition and their research module performance as part of a Bachelor of Education degree (B.Ed.) curriculum is also established. This study contributes to the development of best practices and the advancement of institutional research development across HEI; it also stimulates interdisciplinary engagement within the research field research modules at HEI in South Africa.
\end{abstract}

Keywords: explicit learning processes, high frequency, incidental, learning processes, performance, research, undergraduate students, vocabulary acquisition

\section{Introduction}

It is generally acknowledged that the South African schooling system does not sufficiently prepare students for the demands raised by higher education institutions (HEIs) (Cliff, 2014: p. 322; Fouché, 2015: p. 19; Meier, 2011: p. 549; Universities South Africa [USAF], 2008: p. 3; Van Dyk, Zybrands, Cillié, \& Coetzee, 2009: p. 333). Low levels of academic literacy are related to students' insufficient readiness for higher education (HE). Most studies agree that academic literacy is a significant indicator and predictor of students' academic success at HEIs (Archer, 2008: p. 248; Davies, 2009: p. xi; Defazio, Jones, Tennant, \& Hooke, 2010: p. 34; Fouché, 2015: p. 20; Leibowitz, 2010: p. 44; Terraschke \& Wahid, 2011: p. 173). It is also argued by Butler (2013: p. 77) and Jiya (1993: p. 83) that HE academic literacy intervention courses should be based on or integrated into the disciplines students study.

The acquisition of academic literacy is considered an "entry into a new discourse community, where the student is intimately bound up with how to read, write and speak about the discipline" (Goodier \& Parkinson, 2005: 66). 'Literacy' is defined as the ability to read and write (Oxford, 2017: para. literacy), which encompasses the importance of vocabulary as part of the acquisition of academic literacy (Izaks, 2015: p. 1). This study investigates the important role that discipline-specific vocabulary, in the research discipline plays in determining students' performance in research modules. The study also accumulates evidence on students' challenges and concerns with regard to a research module.

According to the Department of Higher Education and Training (DHET, 2015: p. 20), the Bachelor of Education degree (B.Ed.) requires:

intellectual independence and the development of research competence at an introductory level in the field of education, specifically teaching and learning, in order to provide a basis for postgraduate studies in the field of education or in a sub-field of education, as well as for further professional development as a teacher.

The Minimum Requirements of Teacher Education Qualifications (MRTEQ) also "encourages teacher educators to become engaged in curriculum design, policy implementation and research" (DHET, 2015: p. 8). Being a "scholar, researcher and lifelong learner" is also part of the seven roles of teachers as advocated for in the National Qualifications Framework (NQF) Act (67/2008) (DHET, 2015: pp. 58-9). 
From the above, it can be noted that research is a prerequisite within the B.Ed. curriculum for South African students. Therefore, two research modules are included in the fourth year of studies in the B.Ed. curriculum at the private HEI of this study. The first research module includes theoretical information about research and research methodology (e.g. the cyclical process of research, different research designs, data collection, -analysis and -sampling methods, etc.). The second module focuses on analysing and writing a literature review as well as designing a research proposal on an identified problem within education.

\subsection{Conceptual Framework}

Students lack the necessary academic literacy skills that enable them to cope independently with the demands of various academic curricula at university (Cliff, 2014: p. 322; Fouché, 2015: p. 19; Meier, 2011: p. 549; USAF, 2008: p. 3; Van Dyk et al., 2009: p. 333). Butler (2013: 75) regards 'academic literacy' as problematic, since it is not a 'unitary concept'. However, it is important to define academic literacy, since the way academic literacy is defined will influence the design approach of academic literacy interventions. Weideman (2003: p. xi) attempts to define academic literacy in a generic manner as the "accessing, processing and producing of information", with the focus on general tasks that students should perform in the HE context (Butler, 2013: p. 75).

In this study, low levels of academic literacy relate to poor language proficiency; specifically, a lack of discipline-specific vocabulary. According to Izaks (2015: p. 22) a student's vocabulary knowledge influences their ability to learn. A student requires sufficient academic vocabulary "in order for students to cope with the linguistic demands of academic studies" (Izaks, 2015: p. 22). Therefore, vocabulary can influence a student's learning, especially in a module such as research (as in the case of this study).

\subsection{Influence of Vocabulary on Learning}

Vocabulary knowledge is essential because it conveys meaning and comprehension (Schmitt, 2008: p. 329). Bonk's (2012: p. 17) and Laufer (1997: p. 21) consider 95\% comprehension of words in academic texts as the threshold for minimum understanding. A study by $\mathrm{Hu}$ and Nation (2000: p. 419) indicates that learners must know at least $98 \%$ of words in written text for sufficient comprehension. Larson-Freeman and Long (2014: p. 40) suggest a figure as low as $90 \%$ for adequate coverage of words in a written text. It is obvious that students need more vocabulary to comprehend written text(s). Students require regular exposure to written language to acquire more vocabulary (Izaks, 2015: p. 42). The written language students get exposed to will determine what type of vocabulary they acquire. There are various types of vocabulary that have an influence on students' learning.

\subsection{Different Types of Vocabulary}

There are five types of vocabulary classified according to their level of frequency or specialised use. The five classifications include: (1) high frequency, (2) mid-frequency, (3) low frequency, (4) academic vocabulary and (5) technical vocabulary (Izaks, 2015: p. 18). 'Frequency' is the rate at which something occurs in a given sample (Oxford, 2017: para. frequency). In this case, the number of times a word appears in spoken language or texts. The word frequency is measured to determine the usefulness of a word (Schmitt \& McCarthy, 1997: p. 19). Frequent words are helpful in comprehending a text without relying on assistance (e.g. using a dictionary) (Izaks, 2015: p. 19). 'Specialised' vocabulary includes academic and technical vocabulary, it refers to "those words that are prevalent in distinct contexts or knowledge domains" (Izaks, 2015: p. 19). Academic vocabulary is commonly used within educational spheres across different disciplines, whereas technical vocabulary is representative of a specific discipline (e.g. research methodology).

According to Schmitt and McCarthy (1997: p. 17), "frequency information provides a rational basis for making sure that learners get the best return for their vocabulary learning effort by ensuring that words studied will be met often". Vocabulary frequency lists should be considered during curriculum design and in determining learning goals for students. The type of vocabulary focused on within this study forms part of technical vocabulary because it relates directly to the research discipline. A vocabulary frequency list (for a research module at a HEI) was established for this study which students had to acquire over a semester and on which they were tested on upon completion of the module.

\subsection{Developing a Frequency List}

Developing a frequency list is not a simple task, and well established criteria should guide the selection of the vocabulary process (Coxhead, 2000: p. 215). According to Schmitt (2008: p. 329), a good starting point is to outline reasonable vocabulary learning goals. When developing a frequency list that will serve as a resource list of high frequency words in a specific discipline, Schmitt and McCarthy (1997: p. 19) suggest considering the following factors:

- Representativeness,

- Frequency,

- Range, 
- Word families,

- $\quad$ Idioms and set expressions, as well as

- $\quad$ Range of information.

First, 'representativeness' requires that the word adequately represent a range of information. 'Frequency' and 'range' refer to the occurrence range across a range of texts. 'Word families' refer to sensible criteria set regarding what forms and uses are counted as members of the same family. 'Idioms and set expressions' mean that some words behave like high frequency words because they are part of multi-word units. Lastly, the 'range of information' refers to the extent or scope of information that a word covers.

To be of use in course design, high frequency word lists need to include the forms and parts of speech included in a word family, the word's underlying meaning, and the variations of meaning as well as the word's collocations (Schmitt \& McCarthy, 1997: p. 19). Other criteria suggested by West (cited in Schmitt \& McCarthy, 1997: p. 19) include the difficulty level learning the words and the necessity of knowing the word's meaning. West (Schmitt \& McCarthy, 1997: p. 19) feels that the difficulty level and necessity of the word should be considered, and that frequency and range alone are not sufficient criteria for deciding what goes into a word list designed for teaching purposes.

The frequency list developed for this study compiled 20 technical vocabularies related to the research discipline. All the criteria mentioned were considered when developing the list. The prescribed textbook used as reading material for the research module formed the corpus from which the technical vocabulary was sampled. Only 20 words were selected due to West's (cited in Schmitt \& McCarthy, 1997: p. 19) suggestion that the level of difficulty should be considered. The selected words for the frequency list are high frequency words within the research discipline, necessary for comprehending the written text within the prescribed textbook. However, the words are abstract to fourth year students enrolled for a research module for the first time. Due to the frequency list's abstract nature, it was deemed necessary to investigate the acquisition process on how the chosen vocabulary was acquired or not acquired throughout the module.

\subsection{Vocabulary Acquisition Process}

Izaks' (2015: p. 36) research shows that the first step in the vocabulary acquisition process is recognising new words. Ellis (1997: p. 2) argues that there are several aspects of vocabulary acquisition which entail different learning processes. Literature suggests two acquisition processes: (1) incidental and (2) explicit learning of vocabulary (Coxhead, 2000: p. 228; Ellis, 1997: p. 2; Izaks, 2015: p. 36; Laufer \& Hulstijn, 2001: p. 4; Schmitt, 2008: p. 346).

\subsection{Incidental Vocabulary Acquisition}

'Incidental vocabulary acquisition' refers to learning vocabulary implicitly and subconsciously through exposure to spoken or written language. Vocabulary acquisition is important to comprehend written texts. Therefore, vocabulary acquisition requires extensive exposure to written language. Incidental vocabulary acquisition is defined by Laufer (2001: p. 47) as the "acquisition of vocabulary as a by-product of another activity" such as reading. Though incidental learning is not a deliberate action to acquire vocabulary, it should not be confused with unfocused learning (Laufer, 2001: p. 44).

The assumption that vocabulary is best learned through incidental learning has its theoretical foundation in Krashen's Monitor Model. A key aspect of this model is the Input Hypothesis (IH) that suggests that successful language acquisition depends on exposure to comprehensible input. Acquisition of vocabulary depends on exposure and is thought to be a natural process rather than an artificial language learning process (Raptis, 1997: p. 576). According to Krashen's (1989: p. 454) IH, reading is one of the most efficient means by which to acquire new vocabulary. According to Raptis (1997: p. 657) Krashen's IH also proposes that vocabulary is best acquired by incidental processes such as guessing from context.

Reading is seen as the foundation on which vocabulary acquisition for first language students are built. We acquire most words through exposure to language input (e.g. reading), rather than by explicitly learning vocabulary (Laufer, 2001: p. 44). When investigating vocabulary acquisition, it is also important to consider the association and relationship between reading comprehension and vocabulary. According to Kilian, Nagy, Pearson, Anderson and Garcia (1995: p. 2) the "strong correlational relationship between vocabulary knowledge and reading comprehension" is nothing new. It can be understood that students' vocabulary knowledge will have a strong influence on their ability to comprehend written text(s) such as prescribed readings. Students should be encouraged to do extensive reading in order to assist their vocabulary acquisition and in turn their reading comprehension (Ellis, 1997: p. 10; Izaks, 2015: p. 42).

Though research has produced positive findings when implementing incidental learning strategies for the acquisition of vocabulary, there is opposing research that has found 'low pick-up' vocabulary rates when only using incidental learning for the purpose of learning new vocabulary. According to Schmitt (2008: p. 347) literature shows that 
incidental vocabulary learning from reading is more likely to "push words to a partial rather than full level of mastery, and that any recall learning is more prone to forgetting than recognition learning". Thus, extensive reading can improve spelling, but gaining meaning and grammatical knowledge occurs only to a lesser degree (Izaks, 2015: p. 38). Horst, Cobb and Meara (1998: p. 207) and Raptis (1997: p. 571) are also of the opinion that incidental reading disregards the didactical influences of parents and peers that might influence vocabulary acquisition. They are also of the opinion that incidental learning is only a 'well-reasoned argument' and that it does not have enough experimental evidence. Horst et al. (1998: p. 210) state that incidental vocabulary acquisition lacks substantive support.

Despite research (Horst et al., 1998: p. 213; Laufer, 2005: p. 244; Raptis 1997: p. 569; Schmitt, 2008: p. 347) showing discouraging rates of vocabulary acquisition when extensive reading (i.e. incidental learning) is utilised for vocabulary acquisition, results of various other studies (Brown, Waring, \& Donkaewbua, 2008: p. 156; Horst, 2005: p. 373; Kilian et al., 1995: p. 12; Mirzaii, 2012: p. 10; Senoo \& Yonemoto, 2014: p. 16; Waring \& Takaki, 2003: p. 153) have found encouraging results. Horst (2005: p. 376) found that his participants gained more than half of unfamiliar vocabulary through extensive reading. Given the fact that the superiority of either incidental or explicit learning is still debated and unresolved it reveals the importance of not only considering one of the two learning processes but both.

\subsection{Explicit Vocabulary Acquisition}

'Explicit vocabulary acquisition' refers to direct and systematic instruction (the conscious teaching and learning of vocabulary) while focusing on a word's range of meanings. Explicit learning forms part of the notion that the more a student is actively working with the word, the more likely the word will be learnt (Ellis, 1997: p. 2; Izaks, 2015: p. 20). According to Ellis (1997: p. 14), Laufer, (2005: p. 244) and Schmitt (2008: p. 347), a word's meaning is not learnt through exposure alone. Therefore, exposure assists in students learning the word's form; word class; collocations, associations or connotations and not the range of meanings of a word (Izaks, 2015: p. 36).

According to Laufer (2005: p. 226) vocabulary requires explicit learning processes since:

- Learners who understand the overall message often do not pay attention to the precise meanings of individual words.

- Unfamiliar words might be confusing in structure and form and lead to misperceptions.

- Students' unawareness of unfamiliar words because of misperceptions of similar words.

- Inferring words from context are often unreliable, especially if the student does not know $98 \%$ of the words in the text.

- When encountering unfamiliar words in longer and more difficult text, students will most probably ignore and/or skim over them.

- $\quad$ To infer words from context may not be enough engagement with the word's form and meaning in order to learn and remember them in the long-term. However, this is in contrast with Krashen's (2013: p. 37) statement that explicit instruction might only have short-term effects and may not be long lasting.

- Laufer's (2005: p. 226) reply to Krashen's (2013: p. 37) criticism is that students need repeated engagement, relatively quickly, with the new words that they have encountered in order to avoid forgetting them.

Regardless of the fact that reading is an educational activity and a means of exposure to vocabulary, it is seen as fundamental for vocabulary learning. Laufer (2001: p. 46) agrees with the importance of reading as input, but argues that there is more evidence pointing to the superiority of explicit teaching of vocabulary. Though explicit learning of vocabulary is regarded by some researchers as the most effective in promoting vocabulary learning, especially for second language learners, there are limitations in the amount of times direct instruction contact can take place. Thus, the importance of incidental learning is emphasised where students have to enhance their own vocabulary knowledge through extensive exposure generated by a meaning-focused input such as reading (Schmitt, 2008: p. 346).

\subsection{Study's Vocabulary Acquisition Approach}

From the above, it can be noted that vocabulary can be acquired incidentally or explicitly. The effectiveness of incidental and explicit vocabulary learning processes are both debated. Major concerns with incidental learning process relate to the amount of time and number of exposures needed for vocabulary to be acquired. Explicit vocabulary learning concerns also relate to the learning process' timeous nature and the fact that it is not practical or realistic to explicitly teach and learn all the vocabulary required by university students.

Izaks (2015: p. 36) is of the opinion that full mastery of a word is due to a combination of these learning processes. Laufer and Hulstijn (2001: p. 22) and Schmitt (2008: p. 352) recommend that advantage be taken of both explicit and incidental learning approaches. However, the study's focus was on the incidental learning process of acquiring adequate 
vocabulary related to the research discipline. A mostly incidental learning was chosen due to direct instruction time constraints and the distance learning module of the HEI. Incidental vocabulary learning took place through extensive reading. Extensive reading was required of students before every weekly lecture.

The type of vocabulary greatly depends on the context in which it is used or learnt (Izaks, 2015: p. 34). According to Schmitt and McCarthy (1997: p. 12), context learning is "the most important vocabulary learning strategy". Vocabulary pertaining to a specific topic or context could be explicitly learned by highlighting the target vocabulary in the text that the students have to read and then paying particular attention to the words by discussing their form, meaning and additional features (Izaks, 2015: p. 42). During the study, students were asked to have group discussions, as well as to complete small online activities related to the target vocabulary in their prescribed reading. Students received one hour of direct instruction a week during a class lecture were the prescribed reading (from which the target words were sampled) was discussed. This teaching approach aligned with Horst et al.'s (1998: p. 220) belief that students can get multiple exposures through direct vocabulary instruction (i.e. explicit learning) that complements reading assignments, such as prescribed reading (i.e. incidental learning).

Though the students received some form of explicit learning of the target vocabulary, due to explicit learning time constraints they mostly had to do extensive reading (i.e. incidental learning) to acquire the vocabulary. Laufer and Hulstijn's (2001: p. 10) argue that incidental vocabulary acquisition investigations require participants to perform a task without being told in advance that they will be tested afterwards on their information recall. In this study, the students were never informed about the target vocabulary and were not informed that they were going to be tested at the end on their research vocabulary - also indicating that the learning process was mostly incidental. The incidental learning focus was also due to the nature of the setting. The study's participants, studied at a private, distance, HEI with limited direct instruction time and more individual, home-based learning.

\section{Methods}

This study tested students' discipline-specific vocabulary in the field of research methodology. It also measured the success of acquiring the selected technical target vocabulary by implementing a mostly incidental learning process throughout the semester.

\subsection{Research Design}

The study's design can be considered quantitative, since Creswell (2012: p. 13) and Grosser (2016: p. 246) confirm that tests are part of quantitative data collection methods. This study aimed to determine relationships and correlations between variables (e.g. vocabulary and performance) - that forms part of a quantitative research design (Grosser, 2016: p. 246). A parametric test, the Pearson product-moment correlation ( $\mathrm{r}$ ) was used to determine all the correlations.

According to Lombard and Klopper (2015: p. 4), a 'positivist paradigm' refers to generating data through objective measurements "independent of inferences, such as feelings or opinions", which is associated with quantitative research designs. This study's inquiry strategy was both a positivist and an interpretivist paradigm, since students' opinions and feelings were also investigated through a qualitative research method. Therefore, this study was conducted from a concurrent mixed-method research design-a combination of methods was applied to gather and analyse both qualitative and quantitative data. A mixed-method design suited this study best, because as McMillan and Schumacher (2010: p. 395) explain, one method is sometimes insufficient to answer all the questions of a study. A concurrent mixed-method design allowed for qualitative research to help explain quantitative findings. The design also allows for the investigation of different types of questions (McMillan \& Schumacher, 2010: p. 397). This study had quantitative and qualitative research questions.

The following research questions guided the quantitative aspect of the study's investigations:

- What is the effect of an incidental vocabulary learning process on students' vocabulary growth?

- What is the relationship between students' vocabulary knowledge and their performance in a research module?

The following research questions guided the qualitative aspect of the study's investigations:

- To what extent do students perceive vocabulary as a challenge to the research module?

- How did students experience their first research module?

The mixed-method research design was followed by an institutional case study design. An 'institutional case study' is an intensive study of a specific context (Trochim, Donnelly, \& Arora, 2016: p. 392), such as the unique character of a private HEI and its students, as in this study. This case study investigated students' vocabulary, with regard to a research module at a private, distance and Christian HEI. The HEI began supplying the South African market with qualified teachers after their first graduation in 2016. The HEI uses a mixed-mode delivery for teaching and learning, by means of contact sessions over weekends, self-study and interactive e-Learning. Interaction takes place in the form of lectures, 
workshops, tutor sessions, seminars, discussion groups and individual one-on-one assistance. Most of the students (i.e. 90\%) are Caucasian, Afrikaans First Language speakers with Christian church affiliations and are employed as full-time educators or assistant teachers at private and public schools throughout various South African provinces.

It can be said that the student population is mostly homogeneous with regard to demographic characteristics and not representative of South African society. Case study limitations according to Joubert (2016: p. 163) and McLeod (2008: para. Case study method) relate to generalisation as well as the fact that it is a very timeous research design. Generalisation in this case, was not essential given that this study's purpose was institutional research. The study's focus was to improve the institution's research curriculum and the research ability of its students as future teachers.

\subsection{Research Method}

The study's population consisted of 180, fourth year undergraduate students, all of whom were enrolled for the compulsory research module at the private HEI as part of their B.Ed.-curriculum $(\mathrm{N}=180)$. Only 135 of the participants volunteered and formed part of the non-probabilistic sample of this study. Seven surveys were spoilt and therefore thrown out. Finally, 128 tests formed the sample of the study $(n=128)$. Due to the participants not being randomly selected, the non-probability sampling technique resulted in questionable external validity relating to the sample's ability to represent the population (Trochim et al., 2016: p. 86). The sample consisted of participants with mostly homogeneous characteristics (e.g. race, gender, religion and age) from one private HEI. The participants could be referred to as 'typical' (so described by Trochim et al., 2016: p. 87) of the private HEI population. Thus, the sample does, to a degree, represent the population, which includes all the students at the private HEI. This 'typical' type or homogenous sampling also complemented the study's institutional case study design (Babbie \& Mouton, 2014: p. 281).

Both quantitative and qualitative data collection methods were used to gather data that could assist in answering the research questions of this study. Throughout the semester incidental learning took place by requiring the participants to do extensive close reading, annotate and highlight important vocabulary within their prescribed research textbook and additional notes. The participants were also exposed to the target vocabulary during classroom discussions, online activities and direct instruction during lectures once a week for 16 weeks (only 12 weeks included lectures). Though the participants were aware that they would be tested on their comprehension of the module's content, they were not aware that they would be tested on specific vocabulary at the semester's end (16 weeks later). The study's participants received instruction in their first language, Afrikaans. The prescribed textbook and the research vocabulary testing were also in Afrikaans which excluded any second language learning variables.

\subsection{Pre-Testing Procedure and Instrumentation}

Testing in this study took place through a two-fold process, a pre- and post-test. The pre-test purpose formed part of the quantitative aspect of the study. The purpose of the pre-test (baseline assessment) was to determine students' research vocabulary knowledge prior to completing the first research module. After students volunteered and gave informed consent to participate in the study, they completed an online multiple choice pre-test on a set of 20 target vocabulary that formed part of the sampled frequency list. Multiple choice tests have been widely used in vocabulary testing due to the format being relatively reliable and objective (Read, 2000: p. 76).

This study's multiple choice test involved matching the target vocabulary with what "most closely corresponds to an appropriate synonym or suitable definition" from three options (Read, 2000: p. 76). According to Gyllstad, Vilkaite and Schmitt (2015: p. 278), three options are typical and as in this study include: (1) the suitable definition (the correct answer), (2) the distractor (unacceptable answer) and (3) the remainder. The prescribed reading material formed the corpus from which the research vocabulary and distractors for the multiple choice vocabulary tests were sampled. Although there are advantages with vocabulary multiple choice testing, there are also some clear disadvantages, such as guessing the correct answer or using a process of elimination (Gyllstad, Vilkaite, \& Schmitt, 2015: p. 278). Cooper and Van Dyk (2003: p. 70) also point out that a multiple choice test does not assess students' depth of word knowledge but rather only their word knowledge breadth. The reliability of the multiple choice vocabulary test used in this study was determined through a test-retest process. The reliability was found to $b e r=.524$ with the correlation significance level being 0.01 (two-tailed), showing a positive and moderately strong correlation, meaning that the test has moderate reliability.

\subsection{Post-Testing Procedure and Instrumentation}

The purpose of the post-test was two-fold. The first part of the quantitative post-test was to determine students' vocabulary knowledge after completing the first research module. By the end of the research module (16 weeks later) the students completed a post-test - the same multiple choice vocabulary test used as the pre-test. The second part of the post-test involved students completing an 'exit slip' in the form of a qualitative questionnaire, where students were asked about their concerns, challenges and experiences, after completing the first research module. Since students' 
questionnaires could be influenced by social desirability and fear of reprisals if they gave negative feedback, the 'exit slips' were completed anonymously.

\section{Discussion}

The following section simultaneously discusses the qualitative and quantitative results since the study's mixed-method approach aimed at using various types of questions that would complement, support and strengthen the findings.

\subsection{Data Analysis and Interpretation}

The data analysis and interpretation were guided by qualitative and quantitative research questions that led to the findings with regard to the influence of students' research vocabulary.

\subsection{Influence of Students' Research Vocabulary}

This section's findings were derived from the pre- and post-multiple choice vocabulary test as well as the qualitative questionnaire. IBM SPSS (Version 21) was used as data analysis tool, with a .05 Alpha level for all the statistics. The following means reported for the multiple choice vocabulary, pre- and post-test, range from 0 being the lowest score and 20 being the perfect score. See Figure 1 for the students' pre- and post-test vocabulary scores.

Pre-test $\square$ Post-test

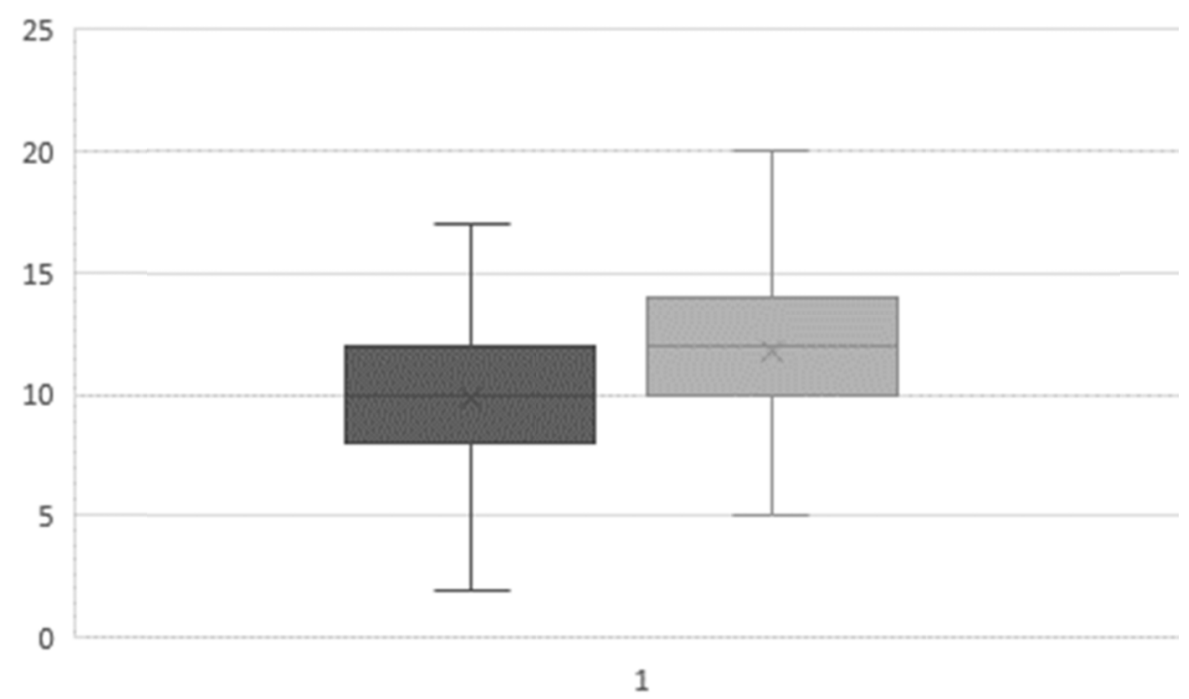

Figure 1. The students' performance scores on the multiple choice vocabulary pre-and post-test

Because the students took both the pre- and post-test on their vocabulary knowledge, the scores are representative of the vocabulary learning and were computed for use in the analyses, to determine the success of the mostly incidental learning process that was implemented throughout the research module. When analysing the graph in Figure 1 the post-test's highest and lowest vocabulary scores are both higher than the pre-tests' corresponding vocabulary scores. The pre-test and post-test scores' distribution is not symmetrical. The pre-test shows more distribution of scores in the lower second quartile and the post-tests show more distribution in the top third quartile. However, the interquartile range of four scores of the pre- and post-test is exactly the same. These results suggest that students performed better in the post-test than the pre-test. In the post-test graph more scores can be located in the upper third and fourth quartiles, meaning that an average of $50 \%$ of students achieved scores above the median (12). See Table 1 for more information regarding difference between the pre- and post-test scores.

Table 1. Statistical information regarding the pre- and post-test

\begin{tabular}{lll}
\hline Statistic & Pre-test results & Post-test results \\
\hline Mean & 9.8 & 11.8 \\
Median & 10 & 12 \\
Mode & 11 & 12 \\
Standard error & 0.267 & 0.247 \\
Standard deviation & 3.031 & 2.802 \\
Minimum & 2 & 5 \\
Maximum & 17 & 20 \\
Range & 15 & 15 \\
Confidence level (95\%) & 0.530 & 0.490 \\
\hline
\end{tabular}


The difference in mean scores between the pre- and post-test of only two, indicates that minor vocabulary growth took place between the pre-test (Week 1) and the post-test (Week 16). 57.8\% of students passed the pre-test and 70.7\% passed the post test, there is thus a $12.9 \%$ difference in pass rates. A two-sample proportions test found an effect size of 0.09 , significant at 0.05 level, indicating no statistically significant growth in students' vocabulary knowledge. It can be inferred that the use of a mostly incidental learning processes did not lead to significant growth in vocabulary knowledge. These findings align with Ellis (1997: p. 14), Laufer (2005: p. 244) and Schmitt's (2008: p. 347) research that incidental learning processes are insufficient since a word's meaning is not learnt through exposure (i.e. incidental learning) alone. Explicit learning is also needed for deeper comprehension. However, the pre- and post-test duration should be considered since 16 weeks might not be enough time for students to show any amount of significant growth. It is also noteworthy to report a 0.48 correlation between the pre- and post-test, indicating a positive and moderate relationship between how students scored during the pre- and post-test.

The small reported effect size (i.e. 0.09) of the students' research vocabulary pre- and post-test scores were further investigated by analysing the participants' post-test, qualitative questionnaires through open-coding and categorising in Atlas.ti, a qualitative analysis software programme. The participants used words translated to English, such as 'confusing', 'difficult to comprehend' and 'challenging' to describe their experiences with regard to the vocabulary found within the prescribed textbook. The vocabulary and prescribed reading were the student's biggest concerns and challenges with regard to the research module.

These findings align with Lombard and Klopper (2015: p. 3)'s research that emphasise students' concerns regarding research vocabulary knowledge. Other challenges and concerns expressed by the students within the qualitative questionnaire included the amount of content and referencing techniques.

\subsection{Influence of Students' Research Vocabulary on Their Final Mark}

Students' overall performance in the module was also determined by calculating their final mark for the semester. See Figure 2 for the distribution of student's final marks for the research module.

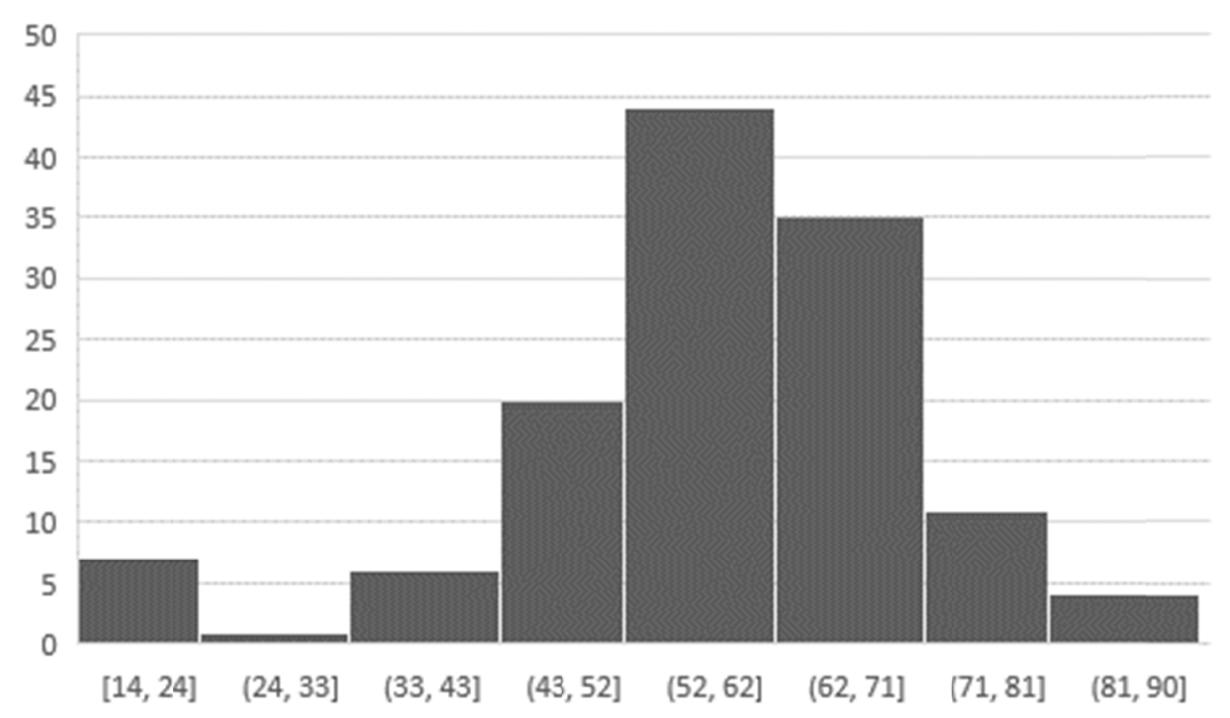

Figure 2. Distribution of participants' final performance of the research module

The mean score was calculated at 61, ranging from 0 to 100 with standard deviation of 13.4. The degree to which vocabulary relates to academic performance was also established through correlation. Each participant's post-test vocabulary score was correlated against their final mark for the module. The research performance mark was calculated as the year mark average, which excluded the participants' examination result. The calculated correlation was 0.09 , showing no relationship between research performance and students' post-test vocabulary score. Though no convincing relationship was established between students' vocabulary knowledge and their overall performance, similar to research done by Izaks (2015: p. 160), a discipline-integrated vocabulary approach is still important since the qualitative results showed how students' lack of understanding the research vocabulary influenced their comprehension of the prescribed textbook. In order to improve students' comprehension and address their concerns regarding the complexity of research vocabulary, the explicit and implicit teaching of research specific vocabulary needs to be integrated. 


\section{Conclusion}

This case study's investigated the influence of undergraduate students' research vocabulary at a private HEI, who enrolled for the first research module as part of their B.Ed.-curriculum. The research considered their discipline-specific vocabulary knowledge and performance with regard to a research module. The study's purpose was to determine if any relationships existed between the variables as well as how the research modules could be improved to help shape future teachers as active researchers in the field of education. The study found (through interpreting qualitative and quantitative data) that research vocabulary form part of students struggles to comprehend the prescribed reading. This finding has implications for the teaching of research modules. Emphasis should be placed on research vocabulary comprehension so that students can work through the prescribed reading with more ease.

Students showed limited growth by using a mostly incidental learning process. This indicates that a balanced approach should be implemented when teaching research vocabulary - using both incidental and explicit learning processes. The relationship between students' vocabulary knowledge and reading comprehension skills could be further investigated. Though this was a case study, the generic nature of undergraduate research modules allows this study's purpose to be transferred or adapted to any other discipline or HEI. More studies such as this can contribute to the development of best practices and the advancement of institutional research development across HEI. They can also stimulate interdisciplinary engagement within the field of research modules at HEI in South Africa.

\section{Acknowledgement}

Dion Van Zyl - Statistical advice and assistance;

Gerrit Kamper - Proof reading and academic advice;

Louise Greyling - Language and technical editing.

\section{References}

Archer, A. (2008). Investigating the effect of writing centre interventions on student writing. South African Journal of Higher Education, 22(2), 248-264. https://doi.org/10.4314/sajhe.v22i2.25784

Babbie, E., \& Mouton, J. (2014). The practice of social research. Cape Town: Oxford University Press.

Bonk, W. J. (2012). Second language lexical knowledge and listening comprehension. International Journal of Listening, 14(1), 14-31. https://doi.org/10.1080/10904018.2000.10499033

Brown, R., Waring, R., \& Donkaewbua, S. (2008). Incidental vocabulary acquisition from reading, reading-while-listening, and listening to stories. Reading in a Foreign Language, 20(2), 136-163.

Butler, G. (2013). Discipline-specific versus generic academic literacy intervention for university education: An issue of impact? Journal for Language Teaching, 47(2), 71-88. https://doi.org/10.4314/jlt.v47i2.4

Cliff, A. (2014). Entry-level students' reading abilities and what these abilities might mean for academic readiness. Language Matters, 45(3), 313-324. https://doi.org/10.1080/10228195.2014.958519

Cooper, T., \& Van Dyk, T. (2003). Vocabulary assessment: A look at different methods of vocabulary testing. Perspectives in Education, 21(1), 67-79.

Coxhead, A. (2000). A new academic word list. TESOL Quarterly, 34(2), 213-238. https://doi.org/10.2307/3587951

Creswell, J. W. (2012). Educational research: Planning, conducting and evaluating quantitative and qualitative research (4th ed.). Boston, MA: Pearson.

Davies, A. (2009). Assessing the academic literacy of additional-language students. Southern African Linguistics and Applied Language Studies, 27(3), xi-xii. https://doi.org/10.2989/SALALS.2009.27.3.2.936

Defazio, J., Jones, J., Tennant, F., \& Hooke, S. A. (2010). Academic literacy: The importance and impact of writing across the curriculum. Journal of the Scholarship of Teaching and Learning, 10(2), 34-47.

Ellis, N. C. (1997). Vocabulary acquisition: Word structure, collocation, grammar, and meaning. In M. McCarthy, \& N. Schmidt (Eds.), Vocabulary: Description, acquisition and pedagogy (pp. 122-139). Cambridge: Cambridge University Press.

Fouché, I. (2015). Towards impact measurement: An overview of approaches for assessing the impact of academic literacy abilities. Stellenbosch Papers in Linguistics, 44(1), 19-35. https://doi.org/10.5774/44-0-164

Goodier, C., \& Parkinson, J. (2005). Discipline-based academic literacy in two contexts. Journal for Language Teaching, 39(1), 66-79. https://doi.org/10.4314/jlt.v39i1.6050

Grosser, M. (2016). Kwantitatiewe navorsing. In I. Joubert, C. Hartell, \& K. Lombard (Eds.), Navorsing: 'n Gids vir die 
beginnernavorser (pp. 245-270). Pretoria: Van Schaik.

Gyllstad, H., Vilkaite, L., \& Schmitt, N. (2015). Assessing vocabulary size through multiple-choice formats: Issues with guessing and sampling rates. ITL International Journal of Applied Linguistics, 166(2), 276-303. https://doi.org/10.1075/itl.166.2.04gyl

Horst, M. (2005). Learning L2 vocabulary through extensive reading: A measurement study. The Canadian Modern Language Review, 61(3), 355-382. https://doi.org/10.3138/cmlr.61.3.355

Horst, M., Cobb, T., \& Meara, P. (1998). Beyond a Clockwork Orange: Acquiring second language vocabulary through reading. Reading in a Foreign Language, 11(2), 207-223.

Hu, M., \& Nation, I. S. P. (2000). Unknown vocabulary density and reading comprehension. Reading in a Foreign Language, 13(1), 403-430.

Izaks, J. (2015). A study of the effects of an undergraduate vocabulary programme on vocabulary development and academic literacy. University of South Africa (Unisa), Pretoria, South Africa.

Jiya, Z. (1993). Language difficulties of black BSc students. South African Journal of Higher Education, 7(1), 80-84.

Joubert, I. (2016). Gevallestudie: Riglyne vir ontwerp en uitvoering van die navorsing. In I. Joubert, C. Hartell, \& K. Lombard (Eds.), Navorsing: 'n Gids vir die beginnnernavorser (pp. 245-270). Pretoria: Van Schaik.

Kilian, A. S., Nagy, W. E., Pearson, P. D., Anderson, R. C., \& Garcia, G. E. (1995). Learning vocabulary from context: Effects of focusing attention on individual words during reading. IL: University of Illinois.

Krashen, S. (1989). We acquire vocabulary and spelling by reading: Additional evidence for the input hypothesis. Modern Language Journal, 73(4), 69-75. https://doi.org/10.1111/j.1540-4781.1989.tb05325.x

Krashen, S. (2013). Reading and vocabulary acquisition: Supporting evidence and some objections. Iranian Journal of Language Teaching Research, 1(1), 27-43.

Larson-Freeman, D., \& Long, M. H. (2014). An introduction to second language acquisition research: Applied linguistics and language study. New York, NY: Routledge.

Laufer, B. (1997). The lexical plight in second language reading: Words you don't know, words you think you know, and words you can't guess. In J. Coady, \& T. Huckin (Eds.), Second language vocabulary acquisition: A rationale for pedagogy (pp. 20-34). New York, NY: Cambridge University Press.

Laufer, B. (2001). Reading, word-focused activities and incidental vocabulary acquisition in a second language. Prospect, 16(3), 44-54.

Laufer, B. (2005). Focus on form in second language vocabulary learning. EUROSLA Yearbook, 5, 223-250. https://doi.org/10.1075/eurosla.5.11lau

Laufer, B., \& Hulstijn, J. (2001). Incidental vocabulary acquisition in a second language: The construct of task-induced involvement. Applied Linguistics, 22(1), 1-26. https://doi.org/10.1093/applin/22.1.1

Leibowitz, B. (2010). The significance of academic literacy in higher education: Students' prior learning and their acquisition of academic literacy at a multilingual South African university. Saarbrücken: Lap Lambert.

Lombard, B. J. J., \& Klopper, M. (2015). Undergraduate student teachers' views and experiences of a compulsory course in research methods. South African Journal of Education, 35(1), 1-14. https://doi.org/10.15700/201503070032

McLeod, S. A. (2008). Case study method. Simply Psychology. Retrieved from http://www.simplypsychology.org/case-study.html

McMillan, J., \& Schumacher, S. (2010). Research in education: Evidence-based inquiry (7th ed.). Boston, MA: Pearson.

Meier, C. (2011). The foundations for learning campaign: Helping hand or hurdle? South African Journal of Education, 31(1), 549-560. https://doi.org/10.15700/saje.v31n4a432

Mirzaii, M. (2012). Implicit vs. explicit vocabulary learning: Which approach serves long-term recall better? The Southeast Asian Journal of English Language Studies, 18(2), 1-12.

Oxford. (2017). Oxford online dictionary. Retrieved from http://www.oxforddictionaries.com/definition/english/literacy

Raptis, H. (1997). Is second language vocabulary best learned by reading? Canadian Modern Language Review, 53(3), 566-580. 
Read, J. (2000). Assessing vocabulary. Cambridge: Cambridge University Press. https://doi.org/10.1017/CBO9780511732942

Schmitt, N. (2008). Review article: Instructed second language vocabulary learning. Language Teaching Research, 12(3), 329-363. https://doi.org/10.1177/1362168808089921

Schmitt, N., \& McCarthy, M. (Eds.). (1997). Vocabulary description, acquisition and pedagogy. Sydney: Cambridge University Press.

Senoo, Y., \& Yonemoto, K. (2014). Vocabulary learning through extensive reading: A case study. The Canadian Journal of Applied Linguistics, 17(2), 1-22.

South Africa, Department of Higher Education and Training (DHET). (2015). National Qualifications Framework Act (67 of 2008): Revised policy on the minimum requirements for teacher. (Government Gazette 38487, Notice 596, 19 February 2015). Pretoria: Government Printer.

Terraschke, A., \& Wahid, R. (2011). The impact of EAP study on the academic experiences of international postgraduate students in Australia. Journal of English for Academic Purposes, 10(3), 173-182. https://doi.org/10.1016/j.jeap.2011.05.003

Trochim, W. M., Donnelly, J. P., \& Arora, K. (2016). Research methods: The essential knowledge base. Boston MA: Cengage Learning.

Universities South Africa (USAF). (2008). Address to the Parliamentary Portfolio Committee on Education. Retrieved from http://www.pmg.org.za/files/docs/080624hesa.pdf

Van Dyk, T., Zybrands, H., Cillié, K., \& Coetzee, M. (2009). On being reflective practitioners: The evaluation of a writing module for first-year students in the health sciences. Southern African Linguistics and Applied Language Studies, 27(3), 333-344. https://doi.org/10.2989/SALALS.2009.27.3.10.944

Waring, R., \& Takaki, M. (2003). At what rate do learners learn and retain new vocabulary from reading a graded reader? Reading in a Foreign Language, 15(2), 130-163.

Weideman, A. J. (2003). Academic literacy: Prepare to learn. Pretoria: Van Schaik.

\section{Copyrights}

Copyright for this article is retained by the author(s), with first publication rights granted to the journal.

This is an open-access article distributed under the terms and conditions of the Creative Commons Attribution license which permits unrestricted use, distribution, and reproduction in any medium, provided the original work is properly cited. 